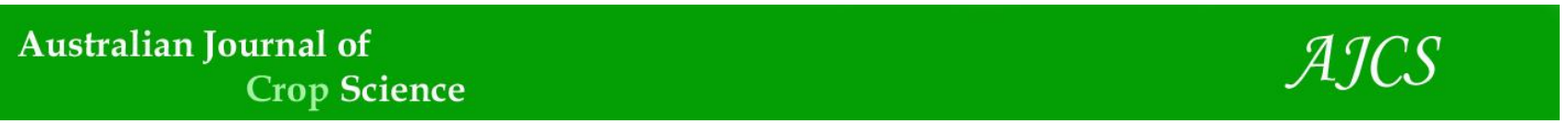

AJCS 14(08):1295-1301 (2020)

ISSN:1835-2707

doi: 10.21475/ajcs.20.14.08.p2562

\title{
Genetic progress in maize from advanced cycles of reciprocal recurrent selection through REML/BLUP
}

\author{
José Arantes Ferreira Júnior, Gabriel Moreno Bernardo Gonçalves, Jocarla Ambrosim Crevelari ${ }^{*}$, Julio \\ Cesar Fiorio Vettorazzi, Vivane Mirian Lanhellas Gonçalves, Nayara Norrene Lacerda Durães, Alexandre \\ Pio Viana and Messias Gonzaga Pereira
}

\author{
Universidade Estadual do Norte Fluminense Darcy Ribeiro/UENF, Laboratório de Melhoramento Genético \\ Vegetal/LMGV, Av. Alberto Lamego, 2000, Parque Califórnia, 28013-602, Campos dos Goytacazes, RJ, Brazil \\ *Corresponding author: jcrevelari@yahoo.com.br
}

Abstract

Breeding methods such as reciprocal recurrent selection (RRS) is very important alternative to breeders. This strategy, besides allowing continuous genetic progress, helps maintaining the genetic variability of populations. The aim of the present study was to estimate genetic parameters, as well as to predict selection gains in advanced cycles of reciprocal recurrent selection of maize progenies through mixed models. Two selection cycles were considered. We evaluated 196 and 169 progenies in the 15 and 16 cycles, respectively. The yield potential of the progenies was evaluated from the following characteristics: grain yield, number of ears, weight of ears and weight of 100 seeds. The estimate of variance components and the prediction of genetic values were based on the REML/BLUP method. Overall, the genetic parameters were increased in the 16th cycle estimates compared to the previous cycle. It is worth highlighting that heritability coefficient for the grain yield was $(0.81)$ in the 16th cycle, since it resulted in $21 \%$ of selection gain. Results showed that, even after sixteen recurrent selection cycles, the populations under selection have high potential for satisfactory genetic gains.

Keywords: Grain yield; Mixed models; Selection gain; Zea mays L.

Abbreviations: REML/BLUP_Restricted Maximum Likelihood/Best Linear Unbiased Prediction; NE_number of ears; EW_ear weight; W100_100-seed weight; GY_grain yield; FSRRS_full-sib reciprocal recurrent selection.

\section{Introduction}

Maize (Zea mays L.) is a cereal that is grown in almost all agricultural regions of the world and is economically and socially extremely important. It is used in food, feed, fuel production and for industrial purposes. The USA is the largest maize producer worldwide, followed by China and Brazil, with an estimated output of 386.74, 216.00 and 83.88 million tons, respectively (USDA 2016). According to estimates, the area of maize cultivation in the 2018/2019 growing seasons in Brazil was 17,242 thousand hectares, producing an estimated yield of 5,524 $\mathrm{kg} \mathrm{ha}^{-1}$, corresponding to an output of 95,254 thousand tons (CONAB 2019).

Grain yield is the most important trait in maize crops; therefore, it should be used as indicator in breeding programs (Hallauer and Carena, 2012). However, genetic gains are hampered, since this trait presents low heritability and complex genetic control (Holland, 2007).

Accordingly, population improvement methods such as the reciprocal recurrent selection (RRS) are a very important alternative to breeders. This strategy, besides allowing continuous genetic progress, helps maintaining the genetic variability of candidate populations. Genetic variability is essential to assure the longevity of breeding programs throughout selection cycles (Hallauer et al., 2010; Souza Junior, 2011). Thus, it is necessary to continuously monitor the genetic parameter variance and estimation components.
REML/BLUP (Restricted Maximum Likelihood/Best Linear Unbiased Prediction) stands out as the most efficient method to estimate genetic value variance and prediction components (Gonçalves et al., 2014, Resende, 2016). This methodology was initially implemented in animal breeding programs. Then, it was adopted in studies about perennial and semi-perennial plant species, since these studies may present loss of field observations, and consequently, unbalanced data (Fritsche-Neto et al., 2010).

Although the aforementioned situation is not very common in annual species trials, the REML/BLUP methodology presents other desirable properties of a good estimator. BLUP minimizes the variance of the error and maximizes the selective accuracy, which are aspects of great relevance in genetic value estimation and prediction processes (Vittorazzi et al., 2017).

For more than two decades, the State University of North Fluminense Darcy Ribeiro, has maintained a full-sib reciprocal recurrent selection program (SRRFIC) in corn. During this period, satisfactory results were obtained with the conduction of this program, which led to the recommendation of improved genotypes for the regional conditions of the North and the Northeast of the Rio de Janeiro State. 
Thus, the aim of the present study was to estimate genetic parameters and to predict selection gain in advanced cycles of full-sib reciprocal recurrent selection (FSRRS) of maize progenies through REML/BLUP.

\section{Results and Discussion}

\section{Deviance analysis}

The deviance analysis was conducted through the LRT test, at $1 \%$ probability level. Results showed significant differences between all tested effects and analyzed traits ( $p$ $<0.01$ ) (Table 1). The genetic variability was observed among genotypes, indicating the possibility of selecting superior individuals, and consequently, achieving genetic improvement in future selection cycles.

\section{Estimates of parameters genetics of the $15^{\text {th }}$ cycle}

Table 2 shows the results of the evaluation applied to 169 full-sib families belonging to the $15^{\text {th }}$ FSRRS cycle. With respect to the variance components, the environment in Campos dos Goytacazes County recorded higher estimates for variables such as GY, NE, EW and W100, besides presenting greater additive variance than the one in Itaocara County. In recurrent selection schemes, where the selection unit is different from the recombination unit, the exploration of the additive genetic variance is determinant factor for the breeding program to be successful.

Heritability is one of the most important genetic parameters, since it quantifies the inheritable phenotypic variation fraction to be explored in the selection process. The narrowsense heritability values of the four traits analyzed in the $15^{\text {th }}$ cycle in Campos dos Goytacazes County were 0.62 (GY) 0.66 (NE), 0.63 (EW) and 0.66 (W100); whereas the estimates in Itaocara County were 0.69 (GY) 0.41 (NE), 0.33 (EW) and 0.74 (W100) (Table 2).

Overall, the herein recorded heritability values were considered adequate due to the polygenic nature of the analyzed traits. This parameter reflects a particular condition, which depends on several factors, such as: estimation method, genetic properties of the population, experimental unit, sample size and accuracy at the time to conduct tests and data collection (Vencovsky and Barriga, 1992).

The selective accuracy (Acprog) depicts the correlation between the predicted and true genetic values of selected progenies (Alves et al., 2018). The trait 'grain yield' recorded Acprog estimates 0.75 and 0.73 when the genotypes were tested in Campos dos Goytacazes and Itaocara counties, respectively (Table 2). According to the classification by Resende and Duarte (2007), these estimates presented high magnitude $(0.70 \leq$ Acprog $<0.90)$.

The environment in Campos dos Goytacazes County recorded significantly higher coefficient of genotype variation between progenies (CVgp) for all evaluated traits than the one in Itaocara County. The traits GY and EW recorded the highest CVgp values, the fact that indicated greater variability and opportunity to obtain genetic improvement in both traits.

Some traits are directly related to productivity and are strongly influenced by the environment. It is worth highlighting that good control of experimental conditions, is reflected on the experimental variation coefficients (CVe).
Genotypes were evaluated in Campos dos Goytacazes County (Table 2) presented values below or close to $20 \%$, and it showed better control over the experimental conduction. Results of the current study showed that only traits ' $G Y$ ' and ' $E W$ ', evaluated in the experiment conducted in Itaocara County, were classified as very high, based on the scale set by Scapim et al. (1995).

All traits recorded significantly higher variation index in Campos dos Goytacazes than in Itaocara, where estimates ranged from 0.78 to 0.82 (Table 2). According to Vencovsky and Barriga (1992), values higher than or close to 1 indicate favorable conditions for superior genotype selection. It is essential using more elaborate strategies such as recurrent selection methods to obtain better results, while the index is lower than 1.

Genotypes analyzed in the environment in Campos dos Goytacazes County showed higher GY (increase by 634.94 kg. ha ${ }^{-1}$ ) than the ones in Itaocara County. However, genotypes evaluated in both environments showed production means higher than the national and Rio de Janeiro State means, which recorded 4,809 $\mathrm{kg} \mathrm{ha}^{-1}$ and 2,600 $\mathrm{kg} \mathrm{ha}^{-1}$, respectively, in the 2015/2016 crop year (CONAB, 2018).

Therefore, only the environment in Campos dos Goytacazes County was taken into consideration for family selection and selection gain prediction in the present recurrent selection cycle, since it presented outstanding progeny performance conditions, besides enabling the highest genetic parameter values (Table 3 ). In addition, progenies were only evaluated in the environment in Campos dos Goytacazes County to enable the $16^{\text {th }}$ FSRRS cycle.

The GY of families selected in the $15^{\text {th }}$ cycle ranged from 7263.33 to $9296.67 \mathrm{~kg} \mathrm{ha}^{-1}$. The variation range was $2,033.34$ $\mathrm{kg} \mathrm{ha}^{-1}$ (Table 3). The comparison between the mean of selected families and the general mean of the test showed yield increase by $1481.47 \mathrm{~kg} \mathrm{ha}^{-1}(\mathrm{sd})$, which resulted in $14 \%$ predicted genetic gain in the aforementioned cycle.

\section{Estimates of parameters genetics of the $16^{\text {th }}$ cycle}

The evaluation of families belonging to the $16^{\text {th }}$ cycle showed that all traits recorded high heritability estimates (Table 4). Also, these traits presented significant increase in comparison to the previous cycle, except for W100 (0.55). It is worth highlighting traits such as grain yield and number of ears, presented the highest heritability values (Table 4). As it was already mentioned, less expressive values are expected due to the complexity of the genetic control of the traits evaluated in the current study. However, the literature has already reported grain yield heritability values close to or higher than $80 \%$ in maize (Baretta et al., 2016; Baretta et al., 2017).

CVgp recorded values between 6.73 (W100) and 9.97 (GY). Traits such as GY and NE presented the highest CVgp. These results show that GY and NW presented the highest genetic variability among the analyzed traits and can provide better results throughout the selection cycles.

The CVs recorded for the environment in Campos dos Goytacazes in the $16^{\text {th }}$ cycle were 19 (GY), 13 (NE), 18 (EW) and 7 (W100). These values are considered adequate for the evaluated traits, since they allow inferring excellent conditions during the experiment. This information is extremely relevant, since the increased experimental accuracy strongly contributes to the obtainment of more 
Table 1. Deviance analysis applied to traits such as number of ears (NE), ear weight (EW), weight of one hundred seeds (W100) and grain yield (GY) in two FSRRS cycles. Darcy Ribeiro State University of Northern Rio de Janeiro, Campos dos Goytacazes County Brazil, 2018.

\begin{tabular}{|c|c|c|c|c|}
\hline \multirow{2}{*}{ Effects } & \multicolumn{2}{|c|}{$\mathrm{NE}$} & \multicolumn{2}{|c|}{ EW } \\
\hline & Deviance & $\operatorname{LRT}\left(\chi^{2}\right)^{(2)}$ & Deviance & $\operatorname{LRT}\left(\chi^{2}\right)$ \\
\hline Cycle & 1680.48 & $720.41^{* *}$ & 802.94 & $1350.42^{* *}$ \\
\hline Families ${ }^{(1)}$ & 1598.63 & $725.63^{* *}$ & 870.36 & $1465.56^{* *}$ \\
\hline Families (Cycles) ${ }^{(1)}$ & 2420.85 & $840.41^{* *}$ & 2086.04 & $951.56^{* *}$ \\
\hline Full Model & 2286.89 & - & 2038.36 & - \\
\hline \multirow{2}{*}{ Effects } & W100 & & GY & \\
\hline & Deviance & $\operatorname{LRT}\left(\chi^{2}\right)$ & Deviance & $\operatorname{LRT}\left(\chi^{2}\right)$ \\
\hline Cycle & 1567.9 & $1102.55^{* *}$ & 1810.37 & $1352.57^{* *}$ \\
\hline Families ${ }^{(1)}$ & 1802.36 & $986.54^{* *}$ & 1652.98 & $1645.78^{* *}$ \\
\hline Families (Cycles) ${ }^{(1)}$ & 2674.35 & $796.63^{* *}$ & 2739.61 & $1125.23^{* *}$ \\
\hline Full Model & 2775.45 & - & 2641.94 & - \\
\hline
\end{tabular}

Table 2. Variance components and genetic parameters through REML/BLUP in the $15^{\text {th }}$ FSRRS cycle in two different environments: Campos dos Goytacazes and Itaocara. Agricultural year 2014/15.

\begin{tabular}{|c|c|c|c|c|c|c|c|c|}
\hline \multirow{2}{*}{ Parameters } & \multicolumn{4}{|c|}{ Campos dos Goytacazes } & \multicolumn{4}{|c|}{ Itaocara } \\
\hline & GY & $\mathrm{NE}$ & EW & W100 & GY & $\mathrm{NE}$ & EW & W100 \\
\hline$V_{P}$ & 4545593.09 & 32.61 & 5.50 & 32.61 & 3076810.22 & 20.65 & 3.59 & 9.03 \\
\hline $\mathrm{V}_{\mathrm{A}}$ & 2857943.92 & 21.82 & 3.51 & 21.82 & 2131984.85 & 8.63 & 1.20 & 6.74 \\
\hline$h^{2}$ & 0.62 & 0.66 & 0.63 & 0.66 & 0.69 & 0.41 & 0.33 & 0.74 \\
\hline Acprog & 0.75 & 0.71 & 0.59 & 0.73 & 0.73 & 0.45 & 0.40 & 0.78 \\
\hline CVgp (\%) & 16 & 12 & 16 & 11 & 2 & 1 & 2 & 2 \\
\hline CVe (\%) & 20 & 15 & 20 & 15 & 30 & 20 & 28 & 11 \\
\hline $\mathrm{VI}$ & 0.82 & 0.78 & 0.81 & 0.78 & 0.07 & 0.07 & 0.07 & 0.19 \\
\hline Mean & 6467.34 & 24.15 & 2.22 & 24.36 & 5832.40 & 22.13 & 2.09 & 25.94 \\
\hline
\end{tabular}

$\mathrm{V}_{\mathrm{p}}$ : Phenotypic variance; $\mathrm{V}_{\mathrm{A}}$ : Additive genetic variance; $\mathrm{h}^{2}$ : Narrow-sense heritability; Acprog: Selective accuracy; $\mathrm{CVgp} \%$ : coefficient of genotype variation between progenies; CVe\%: coefficient of residual variation; VI: variation index; GY: grain yield $\left(\mathrm{kg} \mathrm{ha}^{-1}\right)$; NE: number of ears; $\mathrm{EW}$ : ear weight ( $\left.\mathrm{kg}\right)$; W100: weight of one hundred seeds (g).

Table 3. Selection of the best 30 full-sib corn families belonging to the $15^{\text {th }}$ RRS cycle based on grain yield: Campos dos Goytacazes. Agricultural year 2014/2015.

\begin{tabular}{|c|c|c|c|}
\hline Family & Phenotypic Value & Additive Genetic Value & $\begin{array}{c}\text { Dominance Genetic } \\
\text { Value } \\
\end{array}$ \\
\hline 136 & 9296.67 & 3974.16 & 1324.72 \\
\hline 30 & 8793.33 & 3661.83 & 1220.62 \\
\hline 21 & 8895.56 & 3436.43 & 1145.48 \\
\hline 33 & 8570.00 & 3362.44 & 1120.82 \\
\hline 66 & 8356.67 & 3076.45 & 1025.49 \\
\hline 80 & 8606.67 & 3049.15 & 1016.39 \\
\hline 44 & 8183.33 & 2844.08 & 948.03 \\
\hline 78 & 8183.33 & 2844.08 & 948.03 \\
\hline 9 & 8037.78 & 2648.95 & 882.99 \\
\hline 85 & 8263.33 & 2588.89 & 862.97 \\
\hline 110 & 8223.33 & 2535.26 & 845.09 \\
\hline 12 & 7943.31 & 2522.31 & 840.77 \\
\hline 153 & 7868.89 & 2422.54 & 807.52 \\
\hline 62 & 8060.00 & 2316.30 & 772.10 \\
\hline 7 & 7780.00 & 2303.38 & 767.80 \\
\hline 10 & 7923.33 & 2133.09 & 711.03 \\
\hline 3 & 7916.67 & 2124.15 & 708.05 \\
\hline 77 & 7640.00 & 2115.70 & 705.23 \\
\hline 53 & 7570.00 & 2021.85 & 673.95 \\
\hline 65 & 7773.33 & 1932.00 & 644.00 \\
\hline 14 & 7502.22 & 1930.99 & 643.67 \\
\hline 5 & 7486.67 & 1910.14 & 636.72 \\
\hline 68 & 7717.78 & 1857.52 & 619.18 \\
\hline 46 & 7408.87 & 1805.84 & 601.95 \\
\hline 15 & 7400.00 & 1793.96 & 597.99 \\
\hline 87 & 7623.33 & 1730.91 & 576.97 \\
\hline 142 & 7323.33 & 1691.18 & 563.73 \\
\hline 90 & 7293.33 & 1650.96 & 550.32 \\
\hline 43 & 7560.00 & 1646.01 & 548.67 \\
\hline 26 & 7263.33 & 1610.74 & 536.92 \\
\hline$\hat{x}_{0}$ & 6467.34 & & \\
\hline$\hat{x}_{s}$ & 7948.81 & & \\
\hline ds & 1481.47 & & \\
\hline$h^{2}$ & 0.62 & & \\
\hline SG (\%) & 14 & & \\
\hline
\end{tabular}


Table 4. Variance components and genetic parameters through REML/BLUP in the $16^{\text {th }}$ FSRRS cycle: Campos dos Goytacazes-RJ. Agricultural year 2016/17.

\begin{tabular}{|c|c|c|c|c|}
\hline \multirow{2}{*}{ Parameters } & \multicolumn{4}{|c|}{ Campos dos Goytacazes } \\
\hline & GY & NE & EW & W100 \\
\hline$V_{P}$ & 2799717.01 & 18.01 & 0.27 & 17.01 \\
\hline $\mathrm{V}_{\mathrm{A}}$ & 2680570.38 & 15.17 & 0.22 & 9.41 \\
\hline$h^{2}$ & 0.81 & 0.84 & 0.76 & 0.55 \\
\hline Acprog & 0.87 & 0.78 & 0.80 & 0.48 \\
\hline CVgp (\%) & 10 & 9 & 10 & 7 \\
\hline CVe (\%) & 19 & 13 & 18 & 7 \\
\hline VI & 0.53 & 0.65 & 0.53 & 0.92 \\
\hline Mean & 7528.22 & 24.24 & 2.51 & 30.61 \\
\hline
\end{tabular}

residual variation; VI: variation index; GY: grain yield $\left(\mathrm{kg} \mathrm{ha}^{-1}\right)$; NE: number of ears; $\mathrm{EW}$ : ear weight (kg); W100: weight of one hundred seeds (g).

Table 5. Selection of the best 30 full-sib corn families belonging to the $16^{\text {th }}$ RRS cycle based on grain yield: Campos dos Goytacazes. Agricultural year 2016/2017.

\begin{tabular}{|c|c|c|c|}
\hline Family & Phenotypic Value & Additive Genetic Value & $\begin{array}{c}\text { Dominance Genetic } \\
\text { Value }\end{array}$ \\
\hline 46 & 10775.31 & 3120.66 & 1040.23 \\
\hline 75 & 10772.84 & 3118.21 & 1039.41 \\
\hline 74 & 10123.46 & 2473.42 & 824.48 \\
\hline 54 & 9790.12 & 2103.00 & 701.00 \\
\hline 150 & 9953.09 & 2097.43 & 699.15 \\
\hline 113 & 9933.33 & 2077.81 & 692.61 \\
\hline 163 & 9844.44 & 1989.55 & 663.19 \\
\hline 124 & 9800.00 & 1905.97 & 635.33 \\
\hline 40 & 9503.71 & 1818.61 & 606.21 \\
\hline 62 & 9338.40 & 1693.93 & 564.65 \\
\hline 187 & 9316.05 & 1640.21 & 546.74 \\
\hline 92 & 9441.98 & 1589.94 & 529.98 \\
\hline 84 & 9461.73 & 1570.10 & 523.37 \\
\hline 130 & 9412.35 & 1560.52 & 520.18 \\
\hline 39 & 9224.69 & 1541.58 & 513.86 \\
\hline 146 & 9385.18 & 1533.55 & 511.19 \\
\hline 164 & 9375.31 & 1523.74 & 507.92 \\
\hline 138 & 9402.47 & 1511.26 & 503.76 \\
\hline 95 & 9367.90 & 1476.94 & 492.32 \\
\hline 125 & 9365.43 & 1474.49 & 491.50 \\
\hline 11 & 9103.71 & 1460.90 & 486.97 \\
\hline 53 & 9135.80 & 1453.31 & 484.44 \\
\hline 81 & 9330.86 & 1440.16 & 480.06 \\
\hline 48 & 9076.54 & 1433.93 & 477.98 \\
\hline 71 & 9054.32 & 1411.86 & 470.62 \\
\hline 129 & 9158.02 & 1308.00 & 436.00 \\
\hline 131 & 9128.39 & 1278.58 & 426.20 \\
\hline 68 & 8950.62 & 1269.44 & 423.15 \\
\hline 45 & 8893.83 & 1252.51 & 417.50 \\
\hline 127 & 9074.07 & 1224.64 & 408.22 \\
\hline$\hat{x}_{0}$ & 7528.22 & & \\
\hline$\hat{x}_{s}$ & 9483.13 & & \\
\hline ds & 1954.91 & & \\
\hline$h^{2}$ & 0.81 & & \\
\hline SG (\%) & 21 & & \\
\hline
\end{tabular}

accurate genetic parameter estimates (Ramalho et al., 2012). According to Table 4 , the mean GY in the $16^{\text {th }}$ cycle was $7528.22 \mathrm{~kg} \mathrm{ha}^{-1}$. There was significant grain yield increase in comparison to the mean of the previous cycle $\left(6467.34 \mathrm{~kg} \mathrm{ha}^{-1}\right.$ ) in Campos dos Goytacazes County (Table 2). These results are even more significant when they are compared to the Brazilian ( $5556.2 \mathrm{~kg} \mathrm{ha}^{-1}$ ) and Rio de Janeiro State $\left(2,332 \mathrm{~kg} \mathrm{ha}^{-1}\right)$ means in the $2016 / 17$ crop year (CONAB, 2018). The grain yield increase throughout the cycles is expected because the implementation of successive selection cycles naturally increases the frequency of favorable alleles and has direct impact on the mean of the trait (Hallauer and Carena, 2012).

Results recorded in the evaluation phase were used to select 30 families (Table 5 ) in order to predict genetic progress. The families selected in the $16^{\text {th }}$ cycle presented yields varying from $9,074.07$ to $10,775.31 \mathrm{~kg} \mathrm{ha}^{-1}$; thus, resulting in selection differential 1,954.91 and predicted gain of $21 \%$. This estimate is higher than the ones recorded for the previous cycles, as reported in the current study $\left(15^{\text {th }}\right.$ cycle) 
and by other authors (Tardin et al., 2007; Cunha et al., 2012; Berili et al., 2013).

It is worth emphasizing that the genetic gain herein recorded for GY in the $16^{\text {th }}$ cycle was higher than the ones obtained through other RRS programs. Alves et al. (2015) used two populations deriving from single cross hybrids to conduct the fifth cycle of reciprocal recurrent selection and found 16 $\%$ genetic gain by applying selection intensity $10 \%$. Santos et al. (2005) subjected IG-1 and IG-2 populations to three RRS cycles and recorded genetic gain 4.07\%, whereas Keeratinijakal and Lamkey (1993) subjected BSSS and BSBC1 populations to 11 selection cycles and recorded $6.95 \%$ genetic gain per cycle.

\section{Materials and Methods}

\section{Plant materials}

Data used in the current study were collected in the second stage (progeny evaluation) of a FSRRS program applied to maize based on information concerning the $15^{\text {th }}$ and $16^{\text {th }}$ cycles. The program has been developed by Darcy Ribeiro State University of Northern Rio de Janeiro (UENF Universidade Estadual do Norte Fluminense Darcy Ribeiro) for more than two decades. It was conducted at Federal University of Viçosa (UFV - Universidade Federal de Viçosa) from the $1^{\text {st }}$ to the $5^{\text {th }}$ cycle and, from the $6^{\text {th }}$ to the $16^{\text {th }}$ cycle, it was implemented under the regional conditions of Northern and Northwestern Rio de Janeiro State, thus totaling 16 cycles (Berilli et al., 2013).

Two populations were used to get full-sib families (FSFs), one belonging to heterotic group 'Flint' (CIMMYT population) and the other one belonging to heterotic group 'Dent' (Piranão population). The FSFs tested in the $15^{\text {th }}$ cycle were generated through the crossing between individuals from improved CIMMYT 14 and Piranão 14 groups, whereas the ones tested in the 16th cycle were generated through the crossing between individuals from CIMMYT 15 and Piranão 15 groups.

\section{Evaluation trials of the $15^{\text {th }}$ cycle}

The trials belonging to the $15^{\text {th }}$ cycle of evaluation were conducted in two different environments to evaluate the families composing the $15^{\text {th }}$ cycle.

The first trial was performed at Antônio Sarlo State Agricultural School, in Campos dos Goytacazes County (Northern Rio de Janeiro State). The second was performed at the Experimental Station of Pesagro-Rio, in Itaocara County, in the 2014/2015 crop year. These aforementioned trials followed the $13 \times 13$ lattice square design, with 169 families and 3 repetitions. The experimental units comprised of $3 \mathrm{~m}$-long rows, with $1 \mathrm{~m}$ spacing between rows and 0.20 $\mathrm{m}$ between plants, and it resulted in a final population of 50,000 plants $\mathrm{ha}^{-1}$.

\section{Evaluation trial of the $16^{\text {th }}$ cycle}

The single evaluation trial of the 16 o cycle was applied to the 2016/17 crop year at Antônio Sarlo State Agricultural School, Campos dos Goytacazes County to evaluate families belonging to the $16^{\text {th }}$ cycle. The test comprised of 196 families and followed a $14 \times 14$ lattice square experimental design, with three repetitions, totaling 588 experimental units. These units comprised of $3 \mathrm{~m}$-long rows, with $0.90 \mathrm{~m}$ spacing between rows and $0.20 \mathrm{~m}$ between plants. The final stand comprised of 55,555 plants ha ${ }^{-1}$ after thinning.

\section{Evaluated traits}

The evaluated traits were number of ears (NE); ear weight (EW): obtained by weighing all ears without husk in each plot, in grams; 100-seed weight (W100), in grams, and; grain yield (GY): the grains of each plot were weighed and the resulting values were corrected to $13 \%$ moisture and converted into $\mathrm{kg} \mathrm{ha}{ }^{1}$.

\section{Analyzing mixed models applied to recurrent selection cycles}

All evaluated traits were subjected to deviance analysis, genetic parameters estimation through REML and to genetic values prediction through BLUP, according to the model described by Littell, et al. (2006):

$Y=X r+Z b+W c+Q f(c)+e$,

Where; $Y$ is the observation vector; $r$ is the repetition effect vector (assumed as fixed), $b$ is the block effect vector (assumed as random), $c$ is the recurrent selection cycle effect vector (assumed as random), $f(c)$ is the additive genetic effect vector of families within the selection cycle (assumed as random), and $e$ is the random error effect vector (assumed as random); $X$ is the fixed effect-incidence matrix, $Z$ is the block effect-incidence matrix, $W$ is the selection cycle effect-incidence matrix, $Q$ is the matrix of family effect-incidence within cycles.

The mixed model equations resulted from:

$$
\begin{aligned}
& {\left[\begin{array}{l}
\hat{r} \\
\hat{b} \\
\hat{c} \\
\hat{f} c
\end{array}\right]\left[\begin{array}{cc}
X^{\prime} R^{-1} X & X^{\prime} R^{-1} Z \\
Z^{\prime} R^{-1} X & Z^{\prime} R^{-1} Z+G^{-1} \\
W^{\prime} R^{-1} X & W^{\prime} R^{-1} W+G^{-1} \\
Q^{\prime} R^{-1} X & Q^{\prime} R^{-1} Q+G^{-1}
\end{array}\right]=\left[\begin{array}{c}
X R^{-1} y \\
Z^{\prime} R^{-1} y \\
W^{\prime} R^{-1} y \\
Q^{\prime} R^{-1} y
\end{array}\right]} \\
& y \mid r, V \sim N(X r, V) \\
& b \mid I \sigma_{b}^{2} \sim N\left(0, I \sigma_{b}^{2}\right) \\
& c \mid \sigma_{c}^{2} \sim N\left(0, I \sigma_{c}^{2}\right) \\
& f c \mid \sigma_{f c}^{2} \sim N\left(0, I \sigma_{f c}^{2}\right) \\
& \varepsilon \mid \sigma_{\varepsilon}^{2} \sim N\left(0, I \sigma_{\varepsilon}^{2}\right) \\
& V=Z \sigma_{e}^{2} Z{ }^{\prime}+W I \sigma_{c}^{2} W^{\prime}+Q I \sigma_{f c}^{2} Q^{\prime}+I \sigma_{e}^{2}
\end{aligned}
$$

The deviance analysis was performed as follows, based on the model described by Viana and Resende (2014): $D=-2 \ln (L)$

$\ln (L)=-1 / 2 \ln \left|X^{\prime} V^{-1} X\right|-1 / 2 \ln |V|-1 / 2(y-X m)^{\prime} V^{-1}(y-X m)$, Where $\ln (\mathrm{L})$ is the maximum point of the restricted maximum likelihood logarithm function (REML); $y$ is the vector of the analyzed variable; $m$ is the observation effect vector (assumed as fixed), $X$ is the fixed effect-incidence matrix; and $V$ is the $y$ variance-covariance matrix.

The LRT (likelihood ratio test) was used to test the meaning of the effects, as follows:

LRT: $\mid-2 \ln \left(L_{s e}\right)+2 \ln \left(L_{f m}\right)$,

Where $L_{s e}$ is the maximum point of the maximum likelihood function in the reduced model (without the 
effects) and $L_{f m}$ is the maximum point of the maximum likelihood function in the full model.

\section{REML Estimators for Genetic Parameters}

Phenotypic variance

Additive genetic variance

$$
V_{P}=V_{G}+V_{E}
$$

$V_{A}=\left[g^{\prime} A^{-1} g+\sigma_{e}^{2} \operatorname{tr}\left(A^{-1} C^{22}\right)\right] / q$, where:

tr: matrix trace operator;

q: total number of observations;

Narrow-sense heritability

$$
h_{a}^{2}=\frac{V_{A}}{V_{P}}
$$

Selective Accuracy

$$
\begin{aligned}
& R_{\hat{a} \hat{a}}^{2}=\left(1-\frac{P E V}{V_{A}}\right)^{\frac{1}{2}} \\
& P E V=\operatorname{Var}\left(a-\hat{a}^{\prime}\right)
\end{aligned}
$$

Coefficient of Genetic Variation between Progenies (CVgp)

$$
\operatorname{CVgp}(\%)=\left\lfloor\frac{\left(V_{A}\right)^{\frac{1}{2}}}{\hat{x}}\right\rfloor * 100
$$

Coefficient of Experimental Variation (CV)

Variation Index (VI)

$$
C V(\%)=\frac{\sqrt{\hat{\sigma}_{e}^{2}}}{\hat{x}} * 100
$$

$$
V I=\frac{C V_{g p}}{C V_{e}}
$$

Selection Differential (sd) and Selection Gain (SG)

$$
\begin{aligned}
s d & =\hat{x}_{s}-\hat{x}_{0} \\
S G(\%) & =\left(\frac{s d \cdot h_{a}^{2}}{\bar{x}_{0}}\right) \cdot 100
\end{aligned}
$$

$\hat{x}_{s}=$ Mean of selected full-sib families.

$\hat{x}_{0}=$ Mean of all evaluated families.

$h_{a}^{2}=$ Narrow-sense heritability

All analyses were performed in the Statistical Analysis System (SAS) software version 9.3. The MIXED procedure (PROC MIXED) was adopted to help obtaining REML estimates. The SELEGEN software was used to select the 30 most promising families for grain yield.

\section{Conclusions}

Results of the current study allow stating that new recurrent selection cycles can be carried out using the studied populations, since they are capable of providing significant genetic improvement. The reciprocal recurrent selection method applied to full-sib families is efficient in obtaining high genetic gains, even after 16 selection cycles.

\section{Acknowledgements}

The authors are grateful to Fundação de Amparo à Pesquisa do Estado do Rio de Janeiro (FAPERJ) for their financial support and to Coordenação de Aperfeiçoamento de Pessoal de Nível Superior - Brasil (CAPES) for granting a doctoral scholarship.

\section{References}

Alves NB, Pádua JMV, Dias Kog, Diniz RP, Guedes ML, Cardoso GA, Souza JC (2015) Evaluation of progenies from the fifth reciprocal recurrent selection cycle in maize. Genet Mol Res. 14: 8236-8243.

Alves SA, Peixoto LA, Teodoro PE, Silva LA, Rodrigues EV, Resende MDV, Laviola BG, Bhering LL (2018) Selection of Jatropha curcas families basead on temporal stability and adaptability of genetic values. Ind Crops Prod. 119: 290293.

Baretta D, Nardino M, Carvalho IR, Oliveira AC, Souza VQ, Maia LC (2016) Performance of maize genotypes of Rio Grande do Sul using mixed models. Científica. 44: 403-411. Baretta D, Nardino $M$, Carvalho IR, Pelegrin AJ, Ferrari $M$, Szareski VJ, Barros WS, Souza VQ, Oliveira AC, Maia LC (2017) Estimates of genetic parameters and genotypic values prediction in maize landrace populations by REML/BLUP procedure. Genet Mol Res. 16: 1-4.

Berilli APCG, Pereira MG, Trindade RS, Costa FR (2013) Response to the selection in the 11th cycle of reciprocal recurrent selection among full-sib families of maize. Acta sci. 35: 435-441.

CONAB - Companhia Nacional de Abastecimento (2019). Acompanhamento da safra brasileira de grãos v.6, safra 2018/2019, $n^{\circ}$ 8, oitavo levantamento, Maio 2019. Available at <https://www.conab.gov.br/infoagro/safras/graos/boletim-da-safra-de graos/item/download/26511_f71a37ff14e961c796e00cfb4 84126f3>. Accessed on Jun 12, 2019.

Cunha KS, Pereira MG, Gonçalves LSA, Berilli APCG (2012) Full-sib reciprocal recurrent selection in the maize populations Cimmyt and Piranão. Genet Mol Res. 11: 3398-3408.

Fritsche-Neto R, Gonçalves MC, Vencovsky R, Souza Junior $\mathrm{CL}$ (2010) Prediction of genotypic values of maize hybrids in unbalanced experiments. Crop Breed Appl Biotechnol. 10: 32-39.

Goncalves GM, Viana AP, Amaral Junior AT, Resende MDV (2014) Breeding new sugarcane clones by mixed models under genotype by environmental interaction. Sci Agric. 71: 66-71.

Hallauer AR, Carena MJ, Miranda Filho JB (2010) Quantitative Genetics in Maize Breeding. New York: Springer. 664.

Hallauer AR, Carena MJ (2012) Recurrent selection methods to improve germplasm in maize. Maydica. 57: 266-283.

Holland JB (2007) Genetic architecture of complex traits in plants.

Curr Opin Plant Biol. 10: 156-161.

Keeratinijakal V, Lamkey KR (1993) Responses to reciprocal recurrent selection in BSS and BCSB1 maize populations. Crop Sci. 33: 73-73.

Littell RC, Milliken GA, Stroup WW, Wolfinger RD, Schabenberger O (2006) SAS for mixed models. Cary: North Carolina. 814.

Ramalho MAP, Ferreira DF, Oliveira AC (2012) Experimentação em Genética e Melhoramento de Plantas. Lavras: UFLA. 300.

Resende MDV, Duarte JB (2007) Precision and quality control in cultivar evaluation experiments. Pesq agropec bras. 37 : 182-194.

Resende MDV (2016) Software Selegen-REML/BLUP: a useful tool for plant breeding. Crop Breed Appl Biotechnol. 16: 330-339.

Santos MF, Moro GV, Aguiar AM, Souza Junior CL (2005) Responses to reciprocal recurrent selection and changes in genetic variability in IG-1 and IG-2 maize populations. Genet Mol Biol. 28: 781-788. 
Scapim CAS, Carvalho CGP, Cruz CDA (1995) Proposal of variation coefficient classification for corn growing. Pesq Agropec Bras. 30: 683-686.

Souza Junior CL (2011) Cultivar development of allogamous crops. Crop Breed Appl Biotechnol. 11: 8-15.

Tardin FD, Pereira MG, Gabriel APC, Amaral Junior AT, Souza Filho GA (2007) Selection index and molecular markers in reciprocal recurrent selection in maize. Crop Breed Appl Biotechnol. 7: 225-233.

USDA - United States Department of Agriculture (2016). Available at<https://www.usda.gov/>. Accessed on April 2, 2018.
Vencovsky R, Barriga P (1992) Genética Biométrica no Fitomelhoramento. Ribeirão Preto: Sociedade Brasileira de Genética. 496.

Viana AP, Resende MDV (2014) Genética Quantitativa no Melhoramento de Fruteiras. Rio de Janeiro: Interciência. 282.

Vittorazzi C, Amaral Junior AT, Guimarães AG, Viana AP, Silva FHL, Pena GF, Daher RF, Gerhardt IFS, Oliveira GHF, Pereira MG (2017) Indices estimated using REML/BLUP and introduction of a super-trait for the selection of progenies in popcorn. Genet Mol Res. 16: 13-21. 